\title{
Clinical Pharmacokinetics and the Impact of Genetic Polymorphism on a CYP2C19 Substrate, BMS-823778, in Healthy Subjects ${ }^{\mathbb{}}$
}

\author{
Jiachang Gong, Lars Hansen, and Lisa lacono \\ Pharmaceutical Candidate Optimization (J.G.), Innovative Clinical Development CFI (L.H.), and Global Regulatory Safety and \\ Biometrics (L.I.), Bristol-Myers Squibb, Princeton, New Jersey \\ Received October 16, 2017; accepted December 29, 2017
}

\begin{abstract}
BMS-823778 is a potent and selective inhibitor of $11 \beta$-HSD1, an enzyme that regulates tissue-specific intracellular glucocorticoid metabolism and is a compelling target for the treatment of metabolic diseases. Metabolism of BMS- 823778 was mediated mainly by polymorphic CYP2C19, with minor contributions from CYP3A4/5 and UGT1A4. The clinical pharmacokinetics (PK) of BMS-823778 was first investigated in healthy volunteers after single and multiple ascending doses. BMS- 823778 was rapidly absorbed after the oral dose, and systemic exposure at steady state increased proportionally to the dose. Large intersubject variability in BMS-823778 exposure was likely because of the polymorphism of metabolic enzymes. The impact of genetic polymorphism of CYP2C19, UGT1A4, and CYP3A5 on BMS-823778 PK was assessed in healthy Chinese and Japanese
\end{abstract}

subjects, as well as in a human absorption, distribution, metabolism, and excretion study in which all subjects were genotyped either before or after treatment. A clear trend of high exposure and low clearance was seen in poor metabolizers (PMs) of CYP2C19 compared with extensive (EM) and intermediate metabolizer (IM) subjects. The impact of UGT1A4 or CYP3A5 polymorphism on BMS-823778 PK was statistically not significant in CYP2C19 EM and IM subjects; however, in a subject with predicted CYP2C19 PM phenotype, the PK of BMS-823778 was affected significantly by UGT1A4 polymorphism. Overall, BMS- 823778 was safe and well tolerated in healthy subjects after single or multiple oral doses. The PK of BMS-823778 was characterized by rapid absorption, and the systemic clearance directly correlated with the genetic polymorphism of CYP2C19.

\section{Introduction}

$11 \beta$-hydroxysteroid dehydrogenases $1(11 \beta$-HSD1) plays a central role in regulating tissue- specific intracellular glucocorticoid metabolism and mediates in situ production of glucocorticoid cortisol as an alternative path besides the classic hypothalamic-pituitary-adrenal axis (Morgan and Tomlinson, 2010; Anagnostis et al., 2013; Morgan et al., 2014). $11 \beta$-HSD1 is expressed mainly in the liver, pancreas, and adipose tissues, and it catalyzes interconversion between biologically inert cortisone and active cortisol. Several lines of evidence have indicated that reducing cortisol generation from cortisone in tissues by inhibition of $11 \beta$-HSD 1 has the potential to be an efficacious treatment of type 2 diabetes, dyslipidemia, and obesity (Morton, 2010; Sooy et al., 2010; Anderson and Walker, 2013; Morentin Gutierrez et al., 2015).

BMS-823778 is a potent and selective inhibitor of $11 \beta$-HSD1 with an in vitro $\mathrm{IC}_{50}$ value of $\sim 3 \mathrm{nM}$ (Li et al., 2014; Furlong et al., 2016). As part of clinical development, the pharmacokinetics (PK), safety, and tolerability of BMS-823778 were characterized in several clinical studies. First, a combined single/multiple ascending dose study (SAD/MAD) was conducted in healthy volunteers. On completion of the study, it was evident that PK variability across subjects was large, indicating potential involvement of polymorphic metabolizing enzymes. This prompted a reaction phenotyping study that demonstrated that the

https://doi.org/10.1124/dmd.117.078824.

S This article has supplemental material available at dmd.aspetjournals.org. metabolism of BMS-823778 was catalyzed mainly by cytochrome $\mathrm{P} 450$ 2C19 (CYP2C19), with minor contribution from CYP3A4/5 and UGT1A4 (Cheng et al., 2018).

The CYP2C enzymes are clinically important enzymes that metabolize approximately $20 \%$ of all pharmaceutical drugs. CYP2C19 metabolizes S-mephenytoin (the prototypical substrate), proton-pump inhibitors such as omeprazole, diazepam, and the platelet inhibitor clopidogrel (Goldstein, 2001; Lee et al., 2002; Mega et al., 2009) and exhibits several genetic polymorphisms, with large phenotypic interindividual variability in metabolism. Individuals can be categorized as extensive (EMs), intermediate (IMs), and poor metabolizers (PMs) based on their metabolism of mephenytoin. Thus, genetic polymorphisms of CYP2C19 have the potential to influence significantly the pharmacokinetics (PK) and pharmacodynamics of many drugs in clinical use, which could result in adverse drug effects or therapeutic failure (Desta et al., 2002; Wojnowski and Kamdem, 2006; Jiang et al., 2015).

Even though CYP3A5 and UGT1A4 played a minor role compared with CYP2C19 in the clearance of BMS-823778, their contribution could increase significantly in subjects devoid of CYP2C19 functionality. A number of clinical studies have suggested that PK of substrates of CYP3A5 or UGT1A4 could be altered in subjects with polymorphic enzymes (Staatz et al., 2010; Reimers et al., 2016). UGT1A4 is involved in the glucuronidation of many drugs, including lamotrigine, tamoxifen, and clozapine (Ehmer et al., 2004). Substrate-dependent enzyme activity has been shown with different genetic variants (namely $* 2$ and $* 3$ ) of

ABBREVIATIONS: 11 $\beta$-HSD1, 11 -hydroxysteroid dehydrogenase 1; ADME, absorption, disposition, metabolism, and excretion (study); AE, adverse event; AI, accumulation index; AUC, area under curve; CLT, total clearance; EM, extensive metabolizer; IM, intermediate metabolizer; LCMS/MS, liquid chromatography-tandem mass spectrometry; LLOQ, lower limit of quantitation; MAD, multiple ascending dose; PM, poor metabolizer; SAD, single ascending dose. 
UGT1A4 (Reimers et al., 2016). Thus, in addition to the polymorphism of CYP2C19, the impact of UGT1A4 and CYP3A5 polymorphism on the PK of BMS-823778 needs to be evaluated clinically, particularly in subjects with CYP2C19 variations.

A single-dose human absorption, disposition, metabolism, and excretion (ADME) study with $\left[{ }^{14} \mathrm{C}\right] \mathrm{BMS}-823778$ in CYP2C19 EM and PM subjects was reported previously in which greater exposure of BMS-823778 was observed in PMs than in EMs (Cheng et al., 2018). The current studies describe the PK of BMS-823778 in healthy volunteers after single or multiple ascending doses, as well as further assessment of polymorphic impact in healthy Chinese and Japanese subjects with various genotypes of CYP2C19, UGT1A4, and CYP3A5.

\section{Materials and Methods}

All clinical studies were conducted in accordance with Good Clinical Practice as defined by the International Council for Harmonization and in accordance with the Declaration of Helsinki. The protocol, amendments, and consent forms were approved by the Institutional Review Board/Independent Ethics Committee before initiation of each study at their respective sites. In each clinical study, safety assessments included medical review of adverse events (AEs), vital sign measurements, electrocardiograms, physical examinations, and clinical laboratory tests. Administration of each higher dose was contingent on the acceptable safety and tolerability of the previous dose panel.

Genotyping for CYP2C19, CYP3A5, and UGT1A4 was performed on the drug metabolism enzymes and transporters microarray using the DMET Plus Premier pack kits as described previously (Cheng et al., 2018). Plasma and urine concentrations of BMS-8237778 were determined with validated liquid chromatography-tandem mass spectrometry (LC-MS/MS) methods reported previously (Furlong et al., 2016). Details about the methods-including internal standard, method of extraction, high-performance liquid chromatography column and mobile phase, monitored $\mathrm{m} / \mathrm{z}$ transitions, within- and between-day variability-were described therein.

SAD/MAD Study in Healthy Volunteers. This study was a randomized, placebo-controlled, double-blind, single (part A) and multiple (part B) ascendingdose study to assess the safety, tolerability, and PK of BMS-823778 in healthy volunteers. A total of 104 healthy male subjects (102 white and two nonwhite subjects, aged $18-55$ years, body mass index of $18-29 \mathrm{~kg} / \mathrm{m}^{2}$ ) participated in the study. Eight subjects were assigned to each of eight sequential dose panels $(0.1$, $0.5,2,5,12,25,50$, and $100 \mathrm{mg}$ ) in part A. In each panel, subjects were randomly assigned to receive a single oral dose of BMS-823778 $(n=6)$ or placebo $(n=2)$ on day 1 as an oral solution $(0.1-0.5 \mathrm{mg})$ or capsule formulation $(2-100 \mathrm{mg})$. The oral solution was formulated in a vehicle comprising $50 \%$ (v/v) OraSweet SF in water. Blood and urine samples for PK analysis were collected up to 96 hours after dosing in the 0.1- to 5-mg dose panels. In 12- to 100-mg dose panels, blood samples were collected up to 168 hours postdose, and urine samples were collected up to 120 hours postdose.

In part $\mathrm{B}$, eight healthy male subjects were assigned to each of five sequential dose panels $(0.5,2,5,12$, and $25 \mathrm{mg})$, and each subject was administered a oncedaily oral dose of BMS-823778 $(n=6)$ or a matched placebo $(n=2)$ as an oral solution $(0.5 \mathrm{mg})$ or capsule formulation $(2-25 \mathrm{mg})$ for 14 days. Subjects were kept inhouse up to day 21 for safety evaluations and PK sampling. Serial blood samples were collected after dosing on day 1 for 24 hours and on day 14 for up to 168 hours, and 24-hour urine samples were collected after dosing on days 1 and 14 to characterize the PK profile of BMS-823778. Additional blood samples were collected before dosing on days 2, 6, 8,10,12, and 14 to assess for achievement of steady state. Each blood sample was collected into a prelabeled tube containing $\mathrm{K}_{2}$ EDTA as the anticoagulant and was centrifuged for 15 minutes at approximately $1000 \mathrm{~g}$ to harvest plasma.

Clinical PK Study in Healthy Chinese Subjects. This double-blind, placebo-controlled, single- and multiple-dose study was performed to assess the safety, tolerability, and PK in healthy Chinese subjects. Twenty healthy male Chinese subjects (aged 20-55 years, body mass index $19-25 \mathrm{~kg} / \mathrm{m}^{2}$ ) were randomly assigned to each of two dose panels $(2$ and $15 \mathrm{mg})$ and were administered a single oral dose of BMS-823778 $(n=15)$ or placebo $(n=5)$ as a capsule formulation on day 1 . Blood and urine samples were collected for PK analysis over 96 hours postdose. Beginning on day 6 , subjects received oral doses of study medication once daily for 12 days. Blood and urine samples were collected for PK analysis for 24 hours after dosing on day 17. Trough blood samples were also collected predose on days 7, 9, 11, 13, and 15. Detailed procedures for blood collection and plasma harvesting were the same as those in $\mathrm{SAD} / \mathrm{MAD}$ study. Genotyping was performed retrospectively for all subjects who participated in this study. Therefore, the criteria did not pertain to a genotype assessment in advance.

Clinical PK Study in Healthy Japanese Subjects. This randomized, placebo-controlled, double-blind, multiple ascending dose study assessed the safety, tolerability, and PK of BMS-823778 in healthy Japanese subjects. The study consisted of three dose panels $(2,12$, and $25 \mathrm{mg}$ ), and within each panel, eight subjects were assigned randomly in a double-blinded fashion to receive daily oral doses of either BMS-823778 or matching placebo as a capsule formulation for 14 days in a ratio of $3: 1$. Serial blood samples and urine samples were collected up to 24 hours after the first dose on days 1 and up to 168 hours after the last dose on day 14. In addition, trough (predose) samples were collected on days 6, 8, 10, and 12. Detailed procedures for blood collection and plasma harvesting were the same as in the SAD/MAD study. Genotyping was performed retrospectively for all subjects who participated in this study.

Human ADME Study with $\left[{ }^{\mathbf{1 4}} \mathbf{C}\right]$ BMS-823778. Details of the human ADME study with genotyping have been described previously (Cheng et al., 2018). Briefly, 14 healthy male subjects were placed into three groups based on their predicted CYP2C19 phenotype: group 1 (EMs, $n=7$ ), group 2 (PMs, $n=3$,), and group 3 with bile collection 3-8 hours postdose (two EMs and one PM). Each subject received a single oral solution dose of $10 \mathrm{mg}\left[{ }^{14} \mathrm{C}\right] \mathrm{BMS}-823778$ containing $80 \mu \mathrm{Ci}$ of radioactivity. Blood, urine, feces, and bile samples were collected for PK and metabolite analysis. Methods for radioactivity measurement and metabolite analysis have been reported previously (Cheng et al., 2018).

Data Analysis. All subjects in the 0.1- and 0.5-mg dose panels in SAD and all subjects from $0.5 \mathrm{mg}$ MAD group at day $1 \mathrm{had}$ an insufficient number of plasma and urine data above the LC-MS/MS assay lower limit of quantification (LLOQ; $0.2 \mathrm{ng} / \mathrm{ml}$ for the plasma assay and $1 \mathrm{ng} / \mathrm{ml}$ for the urine assay); therefore, neither plasma nor the urine PK parameters have been reported for these dose panels. Likewise, urine PK parameters for subjects in the 2-mg SAD dose panel have not been reported because of low urine concentration.

For the dose panels in SAD/MAD, in which subjects did have enough data above the LLOQ, as well as the Chinese and Japanese studies, the PKs of BMS823778 were derived from plasma concentration versus time and urinary excretion data. Individual subject PK parameter values were derived by noncompartmental analysis using the program Kinetica (Version 5; Thermo Fisher Scientific, Waltham, MA) and summarized by descriptive statistics. Plasma concentration data from all subjects who received BMS-823778 were included in the PK analysis. Predose concentrations and concentrations before the first quantifiable concentration that were below LLOQ were set to zero to calculate the PK parameters but were treated as "missing" for the calculation of summary statistics. The PK parameters $C_{\max }, C_{\min }$, and $T_{\max }$ were recorded directly from experimental observations. Using no weighting factor, the terminal log-linear phase of the concentration-time curve was identified by least-square linear regression of at least three data points. The single-dose half-life of the terminal $\log$-linear phase was calculated as $\ln 2 / \lambda$, where $\lambda$ is the absolute value of the slope of the terminal log-linear phase. The area under the concentration-time curve (AUC) from time zero to the last quantifiable plasma concentration $\mathrm{AUC}(0-\mathrm{T})$ and the area under the plasma concentration-time curve over one dosing interval AUC (TAU) were calculated by mixed log-linear trapezoidal summations. Area under the plasma BMS-823778 concentration-time curve from zero extrapolated to infinity, AUC(INF), was calculated by log- and linear-trapezoidal summations over the collection period, with the last quantifiable plasma concentration being divided by $\lambda$, and the renal clearance CLR/F was calculated as amount of unchanged BMS-823778 recovered in urine/AUC(0-T). The accumulation index (AI) was calculated as AUC(TAU) on day 14/AUC(TAU) on day 1.

Additional statistical analysis was performed with GraphPad Prism (Version 7.03; GraphPad Software, Inc., La Jolla, CA) using unpaired student $t$ test for two group comparisons and ordinary one-way analysis of variance with Dunnett's multiple-comparison test for multiple groups $(n \geq 3)$. Differences were considered significant when $P<0.05$. The dose proportionality of BMS823778 was assessed using a power model, assuming a linear relationship between log-transformed PK exposure parameter [AUC(INF) or AUC(TAU)] and $\log$-transformed dose: $\log (\mathrm{AUC})=\alpha+\beta \log ($ dose $)$. The proportionality constant 


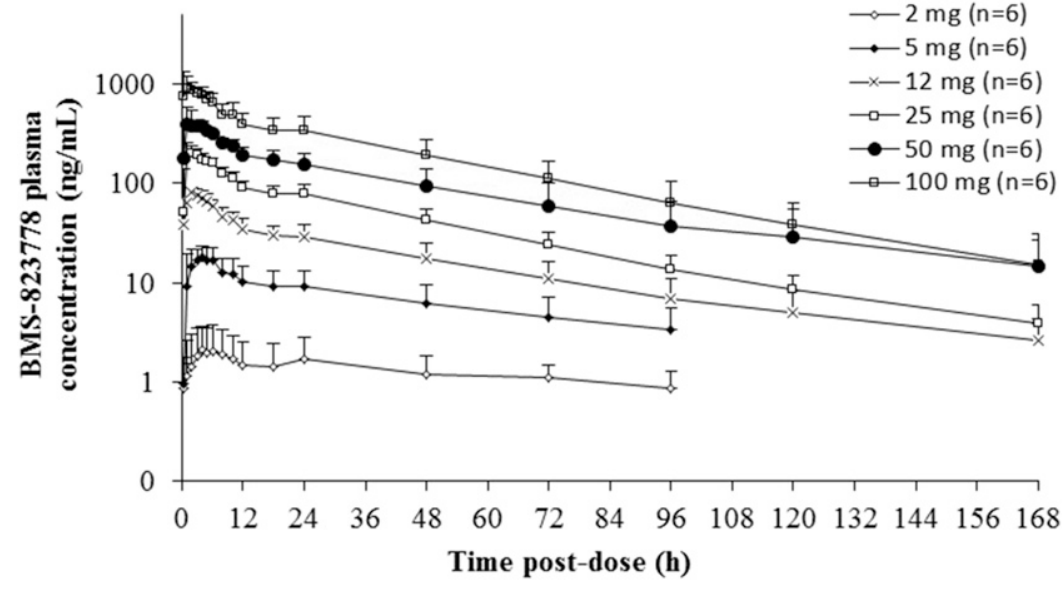

Fig. 1. Mean plasma concentration-time profiles of BMS- 823778 after a single oral dose at the 2- to $100-\mathrm{mg}$ dose range. Subjects in the 0.1 - and $0.5-\mathrm{mg}$ dose panels had insufficient numbers of plasma samples whose concentrations were above the LLOQ of the bioanalytical assay. $(\beta)$ and its corresponding $90 \%$ confidence interval $(\mathrm{CI})$ were estimated from data fitting. Proportionality was concluded if the $90 \%$ CI for $\beta$ was contained completely within $0.8-1.25$ (Smith et al., 2000).

\section{Results}

SAD/MAD Study. Mean plasma concentration versus time plots after a single dose of BMS-823778 are illustrated in Fig. 1, and the PK parameters from noncompartmental analysis are summarized in Table 1. PK samples were collected for 96 hours postdose for 0.1- to 5-mg dose panels, and sampling time was increased to 168 hours starting at the 12-mg dose after the half-life was noted to be longer than predicted. The drug was rapidly absorbed after oral administration, with median $T_{\max }$ values ranging from 1 to 4 hours. The half-life ranged from $\sim 32$ to 50 hours at doses considered to provide a reliable estimate of this parameter (12-100 mg where blood samples were collected for 168 hours after dosing). Dose proportionality was analyzed using a power model, and representative figures are illustrated in Supplemental Fig. S1. The primary analysis suggested a slightly more than doseproportional increase in exposure based on the data collected in all dose panels, including the 2- and 5-mg doses panels of BMS-823778, in which the percentage of extrapolated AUC was $>20 \%$ that of the AUC
(0-T); thus, the AUC(INF) of BMS-823778 at these doses might not be adequately characterized. Additional dose-proportionality analysis was conducted excluding the 2- and 5-mg BMS-823778 dose panels, and results indicated that $\mathrm{AUC}(\mathrm{INF})$ increased dose proportionally $(\beta=$ $1.08,90 \% \mathrm{Cl} 0.95-1.20)$ in the dose ranging from 12 to $100 \mathrm{mg}$. Less than $1 \%$ of the orally administered dose of unchanged BMS-823778 was recovered in the urine. The mean renal clearance of BMS-823778 was estimated to be $<1 \mathrm{ml} / \mathrm{min}$ at all doses studied. Metabolites of BMS823778 in the circulation or urine samples were not measured in this study.

Mean plasma concentrations versus time plots of BMS-823778 after once-daily administration for 14 days are illustrated in Fig. 2, and PK parameters are summarized in Table 2. Exposure of BMS-823778 increased dose proportionally in the tested dose range $(0.5-25 \mathrm{mg}, \beta=$ $1.04,90 \% \mathrm{Cl} 0.96-1.16)$ on day 14 . Considerable overlap in the $C_{\max }$ and AUC(TAU) values between the 12- and 25-mg doses on day 14 and the mean half-life appeared to be shorter ( $~ 35$ hours) at the $25-\mathrm{mg}$ dose relative to lower doses (ranging from 65 to 68 hours). BMS-823778 accumulated in plasma with mean AI values of $~ 21.3,7.3,4.8$, and 3.0, respectively, for the 2-, 5-, 12-, and 25-mg doses of BMS-823778. Trough plasma concentrations (C24h) of BMS-823778 appeared to reach steady-state levels by approximately 12 days.

TABLE 1

Summary statistics of BMS-823778 PK parameters in healthy subjects after a single ascending dose of BMS-823778 in the dose range of $0.1-100$ mg

PK parameters were estimated using a noncompartment method. PK parameters were not calculated for subjects in the 0.1 - and 0.5 -mg dose panels owing to insufficient numbers of plasma samples

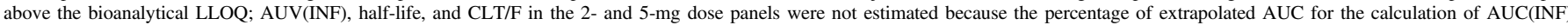
was $>20 \%$ of the $\operatorname{AUC}(0-\mathrm{T})$ values.

\begin{tabular}{|c|c|c|c|c|c|c|}
\hline Treatment Group & $\begin{array}{c}C_{\max }(\mathrm{ng} / \mathrm{ml}) \\
\text { Mean }[n](\mathrm{CV})\end{array}$ & $\begin{array}{c}T_{\max }(\mathrm{h}) \text { Median } \\
{[n](\text { Min-Max) }}\end{array}$ & $\begin{array}{l}\mathrm{AUC}(0-\mathrm{T})(\mathrm{ng} \cdot \mathrm{h} / \mathrm{ml}) \\
\text { Mean }[n](\mathrm{CV})\end{array}$ & $\begin{array}{l}\text { AUC(INF) }(\mathrm{ng} \cdot \mathrm{h} / \mathrm{ml}) \\
\text { Mean }[n](\mathrm{CV})\end{array}$ & $\begin{array}{l}\text { Half-Life (h) } \\
\text { Mean [n] (S.D.) }\end{array}$ & $\begin{array}{c}\text { CLT/F }(\mathrm{ml} / \mathrm{min}) \\
\text { Mean }[n](\mathrm{CV})\end{array}$ \\
\hline $0.1 \mathrm{mg}$ & NA & NA & NA & NA & NA & NA \\
\hline $0.5 \mathrm{mg}$ & NA & NA & NA & NA & NA & NA \\
\hline $2 \mathrm{mg}$ & $1.98[6](73)$ & $3.25[4](2.0-6.0)$ & 109 [6] (54) & NA & NA & NA \\
\hline $5 \mathrm{mg}$ & $19.0[6](22)$ & $2.50[6](1.0-4.0)$ & $612[6](47)$ & NA & NA & NA \\
\hline $12 \mathrm{mg}$ & $84.7[6](14)$ & $1.25[6](0.6-2.0)$ & $2221[6](34)$ & 2389 [6] (36) & $50.4[6](6.09)$ & $83.7[6](41)$ \\
\hline $25 \mathrm{mg}$ & 206 [6] (19) & $1.48[6](0.5-3.0)$ & $5610[6](20)$ & $5837[6](21)$ & $40.3[6](5.77)$ & $71.4[6](21)$ \\
\hline $50 \mathrm{mg}$ & 483 [6] (12) & $1.00[6](1.0-2.5)$ & $12,031[6](41)$ & $12,826[6](48)$ & $43.6[6](14.5)$ & $65.0[6](46)$ \\
\hline $100 \mathrm{mg}$ & 990 [6] (29) & $0.74[6](0.5-2.5)$ & 23,912 [6] (39) & 24,544 [6] (40) & $31.7[6](6.56)$ & 67.9 [6] (34) \\
\hline
\end{tabular}




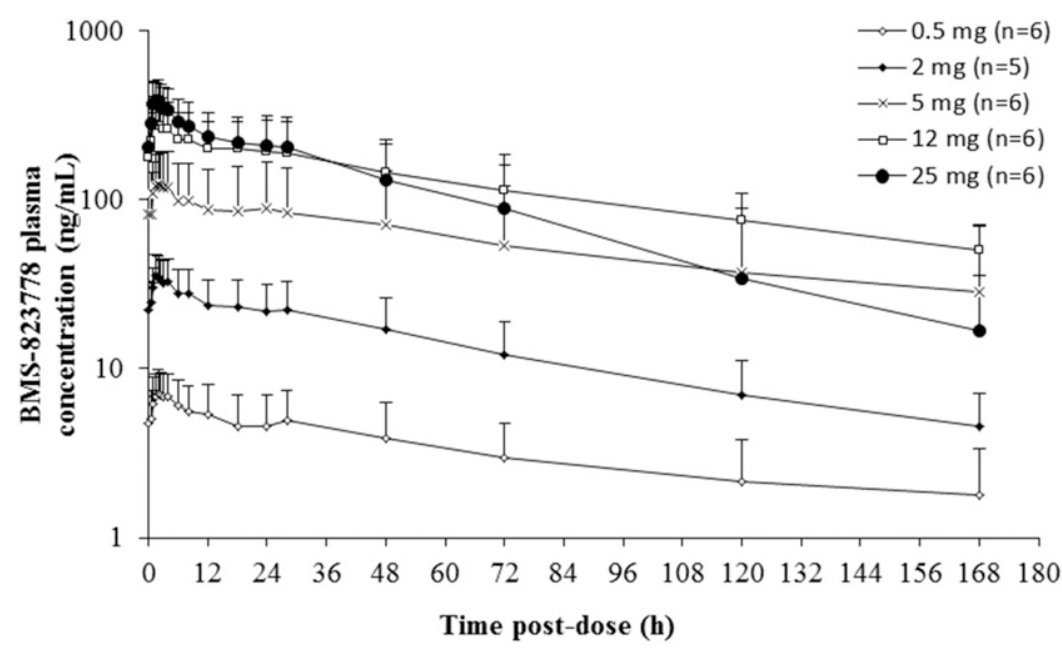

Fig. 2. Mean plasma concentration-time profiles of BMS- 823778 on day 14 after daily doses at 0.5-, 2-, 5-, 12-, and 25-mg dose levels.
PK variability was assessed based on the coefficients of variants $(\mathrm{CV})$ of main PK parameters, including $C_{\max }$, AUC(INF)/AUC(TAU), and total clearance (CLT)/F, as well as the range of these parameters in each dose panel. $\mathrm{CV}$ values were moderate to high, with high value reaching $>70 \%$. Individual exposures of subjects in SAD and MAD are illustrated in Fig. 3. In the same dose panel, there was 2- to 4-fold difference between low and high AUC(INF) or AUC(TAU). In addition, individual exposures at steady state in each dose panel appeared to be segregated into low and high (or low, medium, and high) groups (Fig. 3B).

Secondary peaks were observed in the concentration-time profiles of BMS-823778 at approximately 24 hours postdose in both SAD and MAD (Figs. 1 and 2), presumably owing to the enterohepatic recirculation of the parent or metabolites.

PK Study in Chinese Population. Mean BMS-823778 PK parameters after 2- or 15-mg oral doses to healthy Chinese subjects are summarized in Table 3 . The absorption of BMS-823778 was rapid, with peak concentrations observed approximately 1.5-3 hours after dosing. Mean $C_{\max }$ and AUC(TAU) levels on day 17 of the 15 -mg dose group were $\sim 8$-fold greater than those from 2-mg dose group, indicating an approximate dose-proportional increase in steady-state exposure. Urinary recovery of unchanged BMS-823778 over a 24 -hour interval on day 17 was generally $<1 \%$ of the dose in both groups.
To investigate the effect of polymorphisms on the PK of BMS823778, all subjects participated in the study were genotyped for CYP2C19, UGT1A4, and CYP3A5 after the treatment. Of the 29 participants who received doses of BMS-823778, 9 and 19 subjects were identified as CYP2C19 EMs and IMs, respectively. Only one subject was identified as a poor metabolizer (CYP2C19*2/*3). No subject in this study had the CYP2C19*17 allele (ultrametabolizer).

The PK of BMS- 823778 in Chinese subjects was further analyzed according to their predicted CYP2C19 phenotype. Representative plasma concentration-time profiles of BMS-823778 at $15 \mathrm{mg}$ on day 1 and day 17 are illustrated in Fig. 4 and mean CLT/F values of BMS823778 are tabulated in Table 4 by treatment group and predicted CYP2C19 phenotype. In general, low clearance and high exposure of BMS- 823778 were associated with CYP2C19*2 and *3 variations in Chinese subjects. CLT/F values of BMS-823778 in CYP2C19 EM subjects in both groups on day 17 were significantly higher than in IM subjects (1.7-fold, $P=0.004)$ and $\sim 3.6$-fold higher than in PM subjects.

PK Study in Japanese Population. Similar to the Chinese study, all Japanese subjects were genotyped retrospectively for CYP2C19, CYP3A5, and UGT1A4 polymorphism. Mean PK parameters grouped based on dose levels are summarized in Table 5. BMS-823778 accumulated in plasma on once-daily dosing with mean AI values of

TABLE 2

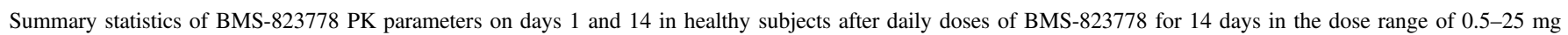

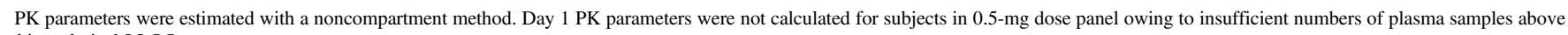
the bioanalytical LLOQ.

\begin{tabular}{|c|c|c|c|c|c|c|}
\hline Treatment Group & Study Day & $\begin{array}{c}C_{\max }(\mathrm{ng} / \mathrm{ml}) \\
\text { Mean }[n](\mathrm{CV})\end{array}$ & $\begin{array}{c}T_{\max }(\mathrm{h}) \text { Median } \\
{[n] \text { (Min-Max) }}\end{array}$ & $\begin{array}{l}\text { AUC(TAU) }(\mathrm{ng} . \mathrm{h} / \mathrm{ml}) \\
\text { Mean }[n](\mathrm{CV})\end{array}$ & $\begin{array}{c}\text { Half-Life (h) } \\
\text { Mean [n] (S.D.) }\end{array}$ & $\begin{array}{c}\mathrm{CLT} / \mathrm{F}(\mathrm{ml} / \mathrm{min}) \\
\operatorname{Mean}[n](\mathrm{CV})\end{array}$ \\
\hline $0.5 \mathrm{mg}$ & $\begin{array}{r}1 \\
14\end{array}$ & $\begin{array}{l}\text { NA } \\
6.81[6](38)\end{array}$ & $\begin{array}{l}\text { NA } \\
3.01[6](1.5-4.0)\end{array}$ & $\begin{array}{c}\text { NA } \\
119 \text { [6] (45) }\end{array}$ & $\begin{array}{l}\text { NA } \\
\text { NA }\end{array}$ & $\begin{array}{c}\text { NA } \\
70.2[2](21)\end{array}$ \\
\hline $2 \mathrm{mg}$ & $\begin{array}{r}1 \\
14\end{array}$ & $\begin{array}{l}1.21[6](67) \\
34.2[5](32)\end{array}$ & $\begin{array}{r}14.9[6](3.0-23.9) \\
2.00[5](1.5-2.5)\end{array}$ & $\begin{array}{l}260[5](52) \\
555[5](40)\end{array}$ & $\begin{array}{c}\text { NA } \\
67.0[5](12.1)\end{array}$ & $\begin{array}{c}\text { NA } \\
60.0[5](35)\end{array}$ \\
\hline $5 \mathrm{mg}$ & $\begin{array}{r}1 \\
14\end{array}$ & $\begin{array}{l}18.7[6](19) \\
114[6](55)\end{array}$ & $\begin{array}{l}1.75[6](1.0-4.0) \\
2.25[6](1.5-4.0)\end{array}$ & $\begin{array}{r}252[6](17) \\
1847[6](72)\end{array}$ & $\begin{array}{c}\text { NA } \\
65.1[6](45.1)\end{array}$ & $\begin{array}{c}\text { NA } \\
45.1[6](17)\end{array}$ \\
\hline $12 \mathrm{mg}$ & $\begin{array}{r}1 \\
14\end{array}$ & $\begin{array}{l}81.4[6](8) \\
276[6](40)\end{array}$ & $\begin{array}{l}1.75[6](1.0-2.5) \\
1.50[6](1.0-2.5)\end{array}$ & $\begin{array}{r}967[6](11) \\
4608[6](52)\end{array}$ & $\begin{array}{c}\text { NA } \\
68.2[6](37.1)\end{array}$ & $\begin{array}{c}\text { NA } \\
43.4[6](43)\end{array}$ \\
\hline $25 \mathrm{mg}$ & $\begin{array}{r}1 \\
14\end{array}$ & $\begin{array}{l}184[6](24) \\
405[6](28)\end{array}$ & $\begin{array}{l}1.00[6](1.0-3.0) \\
1.50[6](0.5-2.0)\end{array}$ & $\begin{array}{l}1999[6](22) \\
5854[6](38)\end{array}$ & $\begin{array}{c}\text { NA } \\
34.7[6](9.11)\end{array}$ & $\begin{array}{c}\text { NA } \\
71.2[6](21)\end{array}$ \\
\hline
\end{tabular}

$\mathrm{CV}$, percent coefficient of variation; $n$, number of subjects with evaluable PK data; NA, not applicable. 
A

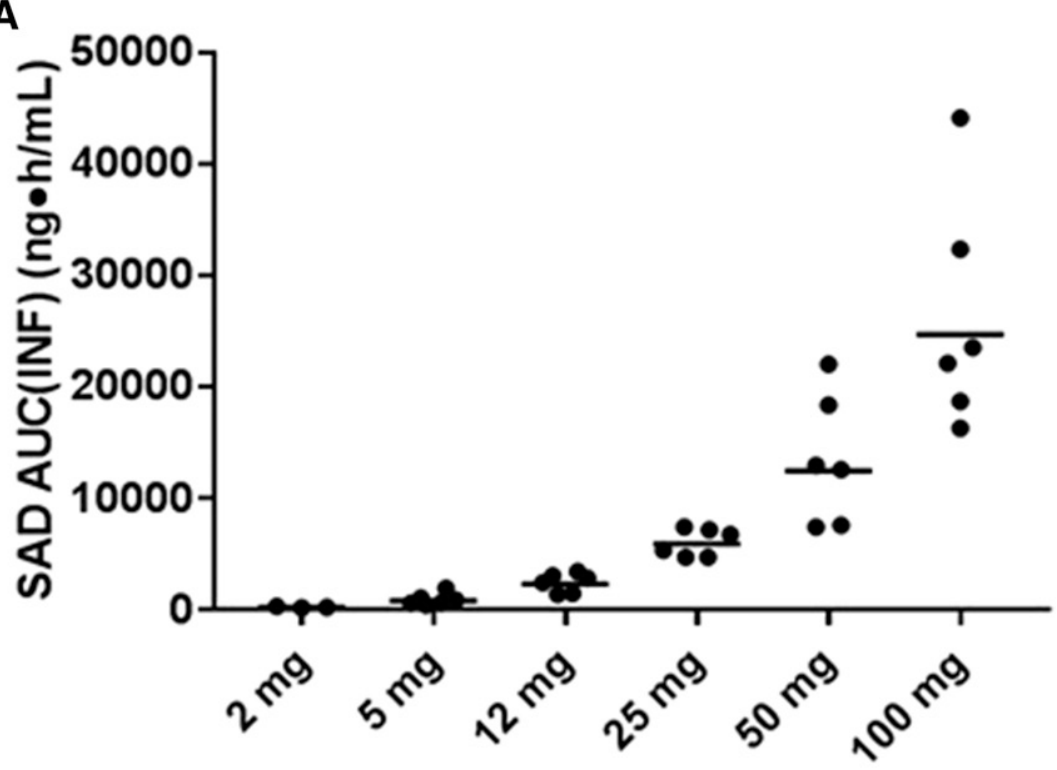

B

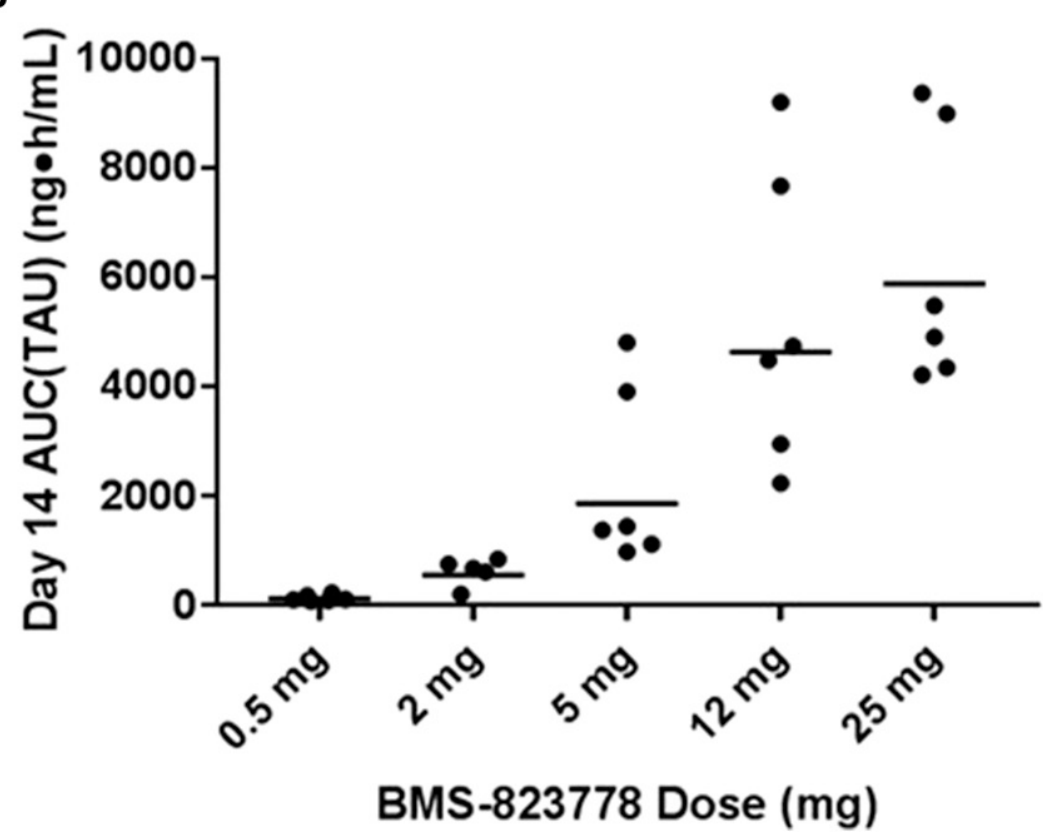

Fig. 3. Individual and mean exposure of BMS- 823778 in subjects after single or multiple doses of BMS-823778: (A) AUC(INF) in SAD panels (2-100 mg); and (B) AUC(TAU) on day 14 in MAD panels $(0.5-25 \mathrm{mg})$.

approximately $21.2,4.17$, and 4.25 for the $2-, 12-$, and $25-\mathrm{mg}$ groups, respectively. Both $C_{\max }$ and AUC(TAU) increased in a doseproportional manner in the dose range of $2-25 \mathrm{mg}$ on day $14(\beta=$
$1.09,90 \% \mathrm{Cl} 0.90-1.21)$. Less than $1 \%$ of the orally administered dose of unchanged BMS- 823778 was recovered in the urine, and the mean renal clearance of BMS-823778 was approximately $0.2 \mathrm{ml} / \mathrm{min}$.

TABLE 3

Summary statistics of BMS-823778 PK parameters in healthy Chinese subjects after a single (day 1) or multiple daily doses (day 17 ) of BMS-823778 at 2 or 15 mg

PK parameters were estimated with a noncompartment method. AUC(INF), half-time, and CLT/F were excluded from the summary if AUC extrapolated $>20 \%$.

\begin{tabular}{|c|c|c|c|c|c|c|c|}
\hline Treatment Group & Study Day & $\begin{array}{c}C_{\max }(\mathrm{ng} / \mathrm{ml}) \\
\text { Mean }[n](\mathrm{CV})\end{array}$ & $\begin{array}{c}T \max (\mathrm{h}) \text { Median } \\
{[n] \text { (Min-Max) }}\end{array}$ & $\begin{array}{c}\text { AUC(TAU) }(\mathrm{ng} \cdot \mathrm{h} / \mathrm{ml}) \\
\text { Mean }[n](\mathrm{CV})\end{array}$ & $\begin{array}{l}\mathrm{AUC}(\mathrm{INF})(\mathrm{ng} \cdot \mathrm{h} / \mathrm{ml}) \\
\text { Mean }[n](\mathrm{CV})\end{array}$ & $\begin{array}{l}\text { CLT/F }(\mathrm{ml} / \mathrm{min}) \\
\text { Mean }[n](\mathrm{CV})\end{array}$ & $\begin{array}{l}\text { Half-Time (h) } \\
\text { Mean }[n] \text { (S.D.) }\end{array}$ \\
\hline \multirow[t]{2}{*}{$2 \mathrm{mg}$} & 1 & $3.66[15](37)$ & $3.00[15](1.00,24.00)$ & $201[15](35)$ & NA & NA & NA \\
\hline & 17 & $57.2[14](33)$ & $2.00[14](0.50,4.00)$ & 965 [14] (40) & NA & $38.3[14](45)$ & NA \\
\hline \multirow[t]{2}{*}{$15 \mathrm{mg}$} & 1 & 157 [14] (19) & $2.00[14](0.50,3.00)$ & 4978 [14] (26) & $4951[8](20)$ & $50.5[8](32)$ & $30.1[8](4.18)$ \\
\hline & 17 & 463 [12] (34) & $1.50[12](1.00,3.00)$ & 7827 [12] (41) & NA & 33.5 [12] (28) & $\mathrm{NA}$ \\
\hline
\end{tabular}

$\mathrm{CV}$, percent coefficient of variation; $n$, number of subjects with evaluable PK data; NA, not applicable. 


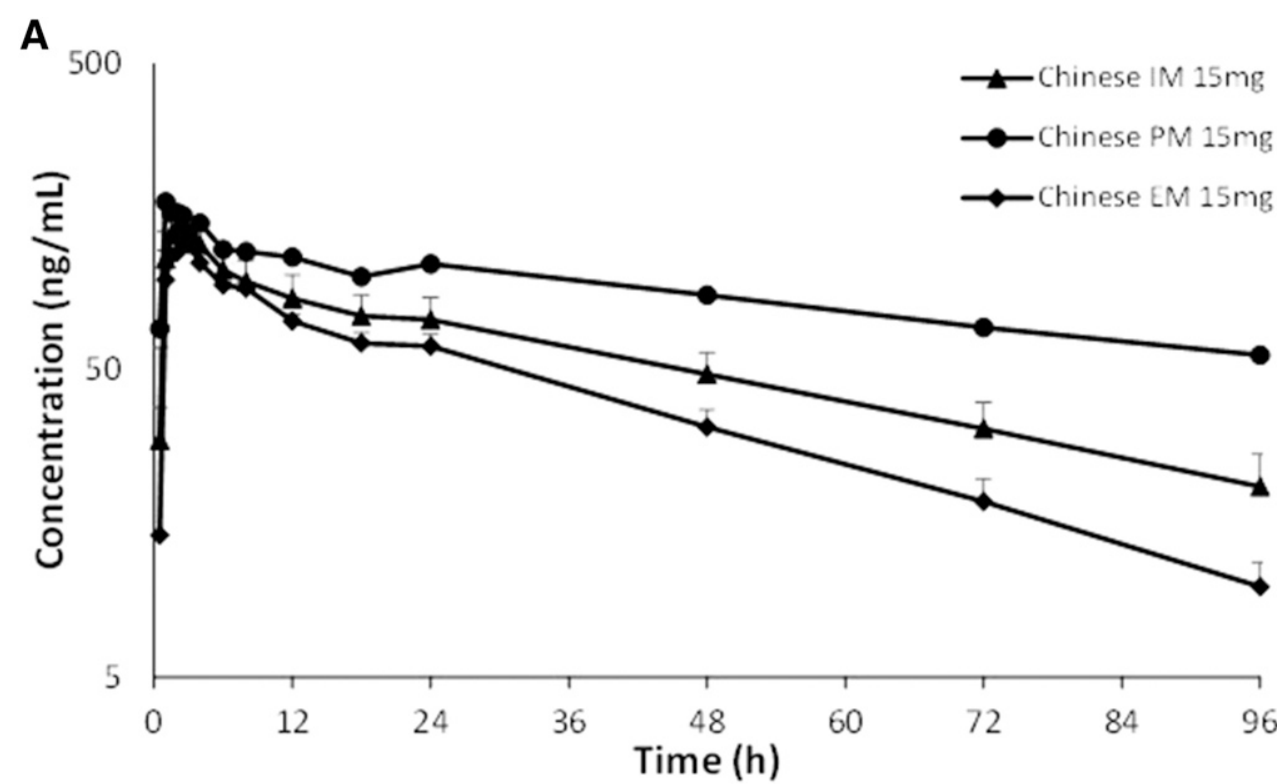

B

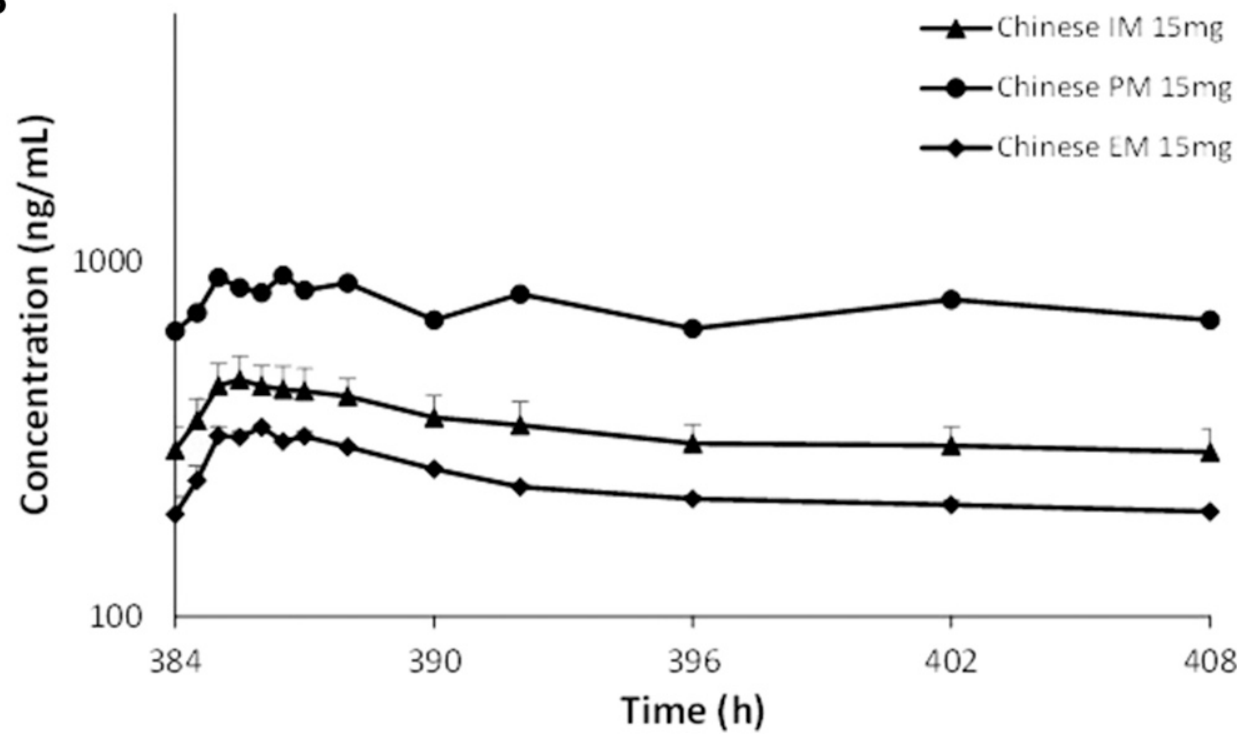

Fig. 4. Representative mean concentrationtime profiles of BMS- 823778 in healthy Chinese subjects with different predicted CYP2C19 phenotype after (A) a single dose of BMS-823778 at $15 \mathrm{mg}$ and (B) daily doses at $15 \mathrm{mg}$ for 12 days.
The PK results were also examined by treatment group and predicted CYP2C19 phenotype. Among a total of 24 healthy Japanese subjects, 6, 15, and 2 subjects were identified as CYP2C19 EMs, IMs, and PMs, respectively. Genotype was not identified in one subject owing to the failure in DNA isolation. No subjects had the CYP2C19*17 allele. Representative plasma concentration-time profiles of BMS-823778 at $12 \mathrm{mg}$ on day 1 and day 14 are illustrated in Fig. 5, and mean CLT/F values of BMS-823778 are tabulated in Table 6 by treatment group and predicted CYP2C19 phenotype. Similar to the Chinese study, high clearance and low exposures were observed in subjects with predicted CYP2C19 EM phenotype compared with IM and PM subjects. Mean CLT/F value in CYP2C19 EM subjects across dosing groups was 1.7 -fold $(P=$ $0.003)$ greater than in IMs and 3.8 -fold $(P<0.001)$ greater than in PMs. When examined by predicted CYP2C19 phenotype, it appeared that steady-state concentrations of BMS-823778 were reached by day 10 of daily dosing for EMs and IMs; however, for PMs, the steady state was not reached at the end of the study.
Dose-proportionality analyses were conducted by CYP2C19 predicted phenotype to evaluate the relationship between overall PK data and CYP2C19 phenotype. Results indicated that the day 14 AUC(TAU) increased largely in a dose proportional manner in the dose range of 2-25 mg in subjects with EM

TABLE 4

Total clearance (CLT/F) of BMS-823778 after the last dose in Chinese subjects by predicted CYP2C19 phenotype and treatment group

\begin{tabular}{cccc}
\hline \multirow{2}{*}{ Dose Level } & \multicolumn{3}{c}{ CLT/F (ml/min) Mean [n] (CV) } \\
\cline { 2 - 4 } & CYP2C19 EM* & CYP2C19 IM & CYP2C19 PM \\
\hline $2 \mathrm{mg}(n=14)$ & $56.7[5](45)$ & $28.1[9](22)$ & NA \\
$15 \mathrm{mg}(n=12)$ & $45.2[3](19)$ & $31.5[8](16)$ & $13.9[1]$ \\
\hline
\end{tabular}

$n$, number of subjects with evaluable PK data; NA, not applicable.

$* P=0.004$ when CLT/F values of EM subjects in both dose groups were compared with IM subjects. 
TABLE 5

Summary statistics for BMS-823778 PK parameters from the Japanese study by treatment group and study day

PK parameters were estimated using a noncompartment method.

\begin{tabular}{|c|c|c|c|c|c|c|}
\hline Treatment Group & Study Day & $\begin{array}{c}C_{\max }(\mathrm{ng} / \mathrm{ml}) \\
\text { Mean }[n](\mathrm{CV})\end{array}$ & $\begin{array}{c}T_{\max }(\mathrm{h}) \text { Median } \\
{[n](\min -\max )}\end{array}$ & $\begin{array}{c}\text { AUC (TAU) }(\mathrm{ng} . \mathrm{h} / \mathrm{ml}) \\
\text { Mean }[n](\mathrm{CV})\end{array}$ & $\begin{array}{l}\text { CLT/F }(\mathrm{ml} / \mathrm{min}) \\
\text { Mean }[n](\mathrm{CV})\end{array}$ & $\begin{array}{c}\text { T-Half (h) } \\
\text { Mean }[n] \text { (S.D.) }\end{array}$ \\
\hline \multirow[t]{2}{*}{$2 \mathrm{mg}$} & 1 & $2.98[6](42)$ & $3.25[6](2.0-6.0)$ & $44.6[6](42)$ & NA & NA \\
\hline & 14 & $57.4[6](58)$ & $1.75[6](1.0-3.0)$ & 944 [6] (72) & 35.3 [6] (44) & $81.8[6](68.8)$ \\
\hline \multirow[t]{2}{*}{$12 \mathrm{mg}$} & 1 & 108 [6] (17) & $1.75[6](1.0-3.0)$ & $1521[6]$ (18) & NA & NA \\
\hline & 14 & 375 [6] (49) & $1.50[6](1.0-3.0)$ & 6348 [6] (61) & 31.5 [6] (54) & $64.6[6](39.2)$ \\
\hline \multirow{2}{*}{$25 \mathrm{mg}$} & 1 & $272[6](16)$ & $1.75[6](1.0-2.5)$ & 3593 [6] (19) & NA & NA \\
\hline & 14 & 931 [6] (46) & $1.50[6](0.5-2.0)$ & $15,276[6](43)$ & 27.3 [6] (34) & $67.5[6](33.2)$ \\
\hline
\end{tabular}

$\mathrm{CV}$, percent coefficient of variation; $n$, number of subjects with evaluable PK data; NA, not applicable.

$(\beta=1.14,90 \% \mathrm{Cl} 0.94-1.19), \operatorname{IM}(\beta=1.12,90 \% \mathrm{Cl} 0.99-1.25)$, or PM $(\beta=$ $0.99,90 \% \mathrm{Cl} 0.56-1.43)$ CYP2C19 phenotype.

Impact of Polymorphisms of UGT1A4 and CYP3A5 on BMS823778 PK. Genetic variations of CYP3A5 and UGT1A4 were observed in CYP2C19 EM and IM subjects in both Chinese and Japanese studies but not in CYP2C19 PM subjects. As illustrated in Fig. 6, no statistically meaningful differences were seen in CLT/F of BMS-
823778 between Chinese subjects with wild-type and polymorphic UGT1A4 $(P=0.28)$ or CYP3A5 $(P=0.34)$. Similar results were observed in the Japanese study, where polymorphism of UGT1A4 and CYP3A5 had no statistically significant impact on BMS-823778 PK in 2C19 EM or IM subjects (Supplemental Fig. S2). For the human ADME study, concentration-time profiles of total radioactivity (TRA) and BMS-823778 after a single dose of $\left[{ }^{14} \mathrm{C}\right] \mathrm{BMS}-823778$ in healthy
A
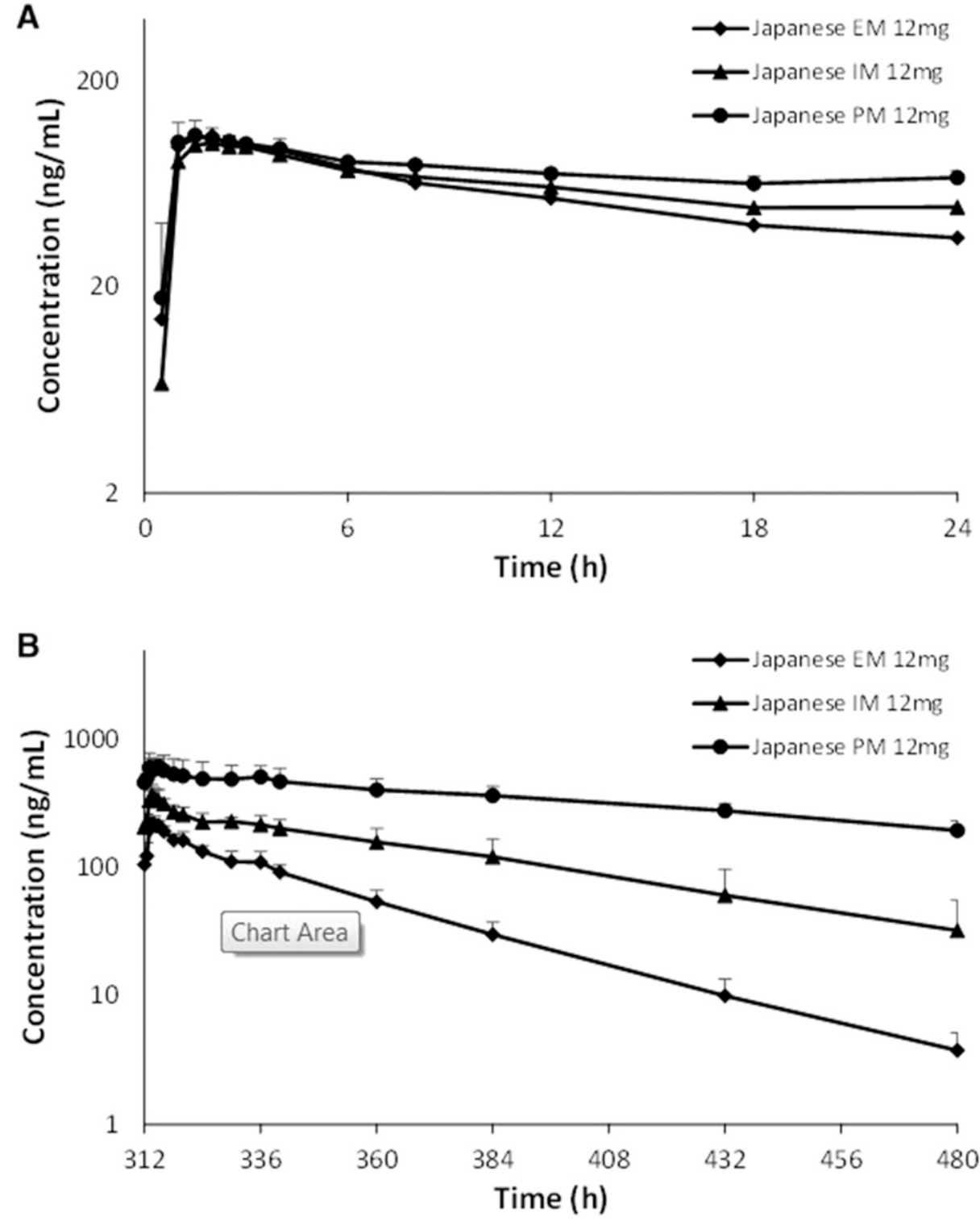

Fig. 5. Representative mean concentration-time profiles of BMS-823778 in healthy Japanese subjects with different predicted CYP2C19 phenotype on (A) day 1 and (B) day 14 after daily oral doses of BMS-823778 at $12 \mathrm{mg}$. 
TABLE 6

Total clearance (CLT/F) of BMS-823778 after the last dose in Japanese subjects by predicted CYP2C19 phenotype and treatment group

\begin{tabular}{clll}
\hline \multirow{2}{*}{ Dose Level } & \multicolumn{3}{c}{ CLT/F (ml/min) Mean $[n](\mathrm{CV})$} \\
\cline { 2 - 4 } & CYP2C19 EM* & CYP2C19 IM** & CYP2C19 PM \\
\hline $2 \mathrm{mg}(n=6)$ & $55.51[2](10)$ & $37.85[3](31)$ & $12.50[1]$ \\
$12 \mathrm{mg}(n=6)$ & $58.47[2](15)$ & $33.13[2](24)$ & $16.68[2](29)$ \\
$25 \mathrm{mg}(n=5)$ & $38.61[2](18)$ & $26.14[2](15)$ & $13.94[1]$ \\
\hline
\end{tabular}

$n$, number of subjects with evaluable PK data; NA, not applicable.

$* P=0.003$ when CLT/F values of EMs across dose groups were compared with these of IMs; $P<0.001$ when CLT/F values of EMs were compared with these of PMs.

$* * P<0.001$ when CLT/F values of IMs were compared with those of PMs

CYP2C19 EM or PM male subjects have been reported previously (Cheng et al., 2018). AUC(INF) of TRA and BMS-823778 were 2.3fold $(P<0.001)$ and 5.3-fold $(P<0.001)$ greater in PMs than in EMs, respectively. Further analysis of BMS-823778 PK was performed based on the genotype of UGT1A4; a scatter plot of AUC(INF) versus corresponding UGT1A4 genotype is illustrated in Fig. 7. The AUC(INF) values in subjects with wild-type or polymorphic UGT1A4 were comparable in CYP2C19 EM group; however, in the CYP2C19 PM group, AUC(INF) was $\sim 50 \%$ greater in a subject with UGT1A $4 * 1 / * 2$ genotype than the mean AUC(INF) of CYP2C19 PM subjects with wildtype UGT1A4. Compared with CYP2C19 EM subjects, there was an $\sim 11$-fold increase in exposure in the subject with both predicted CYP2C19 PM phenotype and polymorphic UGT1A4.

Safety and Tolerability Assessment. BMS-823778 was well tolerated in healthy volunteers. As summarized in Supplemental Tables S1-4, no deaths, severe AEs, or AEs resulting in discontinuation were reported in these studies after a single dose or multiple doses of BMS823778. The investigator and the medical monitor for this study did not identify any clinically relevant safety issues. Most AEs were mild and considered by the Investigator to be not related to study drug. No clinically significant findings or trends in laboratory, vital signs, ECG, or PE assessments were seen.

\section{Discussion}

BMS- 823778 is a potent and selective inhibitor of $11 \beta$-HSD1. The studies described in this article aimed to test the safety, tolerability, and PK in healthy volunteers, as well as to evaluate the polymorphic impact of metabolizing enzymes on the PK of BMS-823778. The first-in-human study for BMS-823778 was a combined SAD/MAD study in healthy male subjects with no genotyping for metabolizing enzymes because the enzymes involved in the metabolism of BMS- 823778 had not been identified before initiation of the study. BMS- 823778 was slowly cleared from human subjects after oral absorption with the mean half-life ranging from $\sim 32$ to 50 hours. Both the $C_{\max }$ and $\mathrm{AUC}(\mathrm{TAU})$ at $25 \mathrm{mg}$ overlapped significantly with those from $12-\mathrm{mg}$ dose panel in MAD, with shorter mean half-life and greater mean CLT/F at the high dose. These findings are unlikely because of cytochrome induction since BMS-823778 is not a CYP3A4 inducer (the details of cytochrome induction are included in the Supplemental Material), and the relatively high clearance at $25 \mathrm{mg}$ was not observed in the Japanese study. One possible explanation is that more CYP2C19 EMs could have been recruited in the 25-mg dose panel in MAD, which increased the mean total clearance.

A dose-proportionality assessment with the power model indicated that the exposure of BMS-823778 increased proportionally with respect to dose, from 12 to $100 \mathrm{mg}$ in SAD and at steady state in MAD from 0.5 to $25 \mathrm{mg}$. The linear PK at steady state was also observed in the Japanese
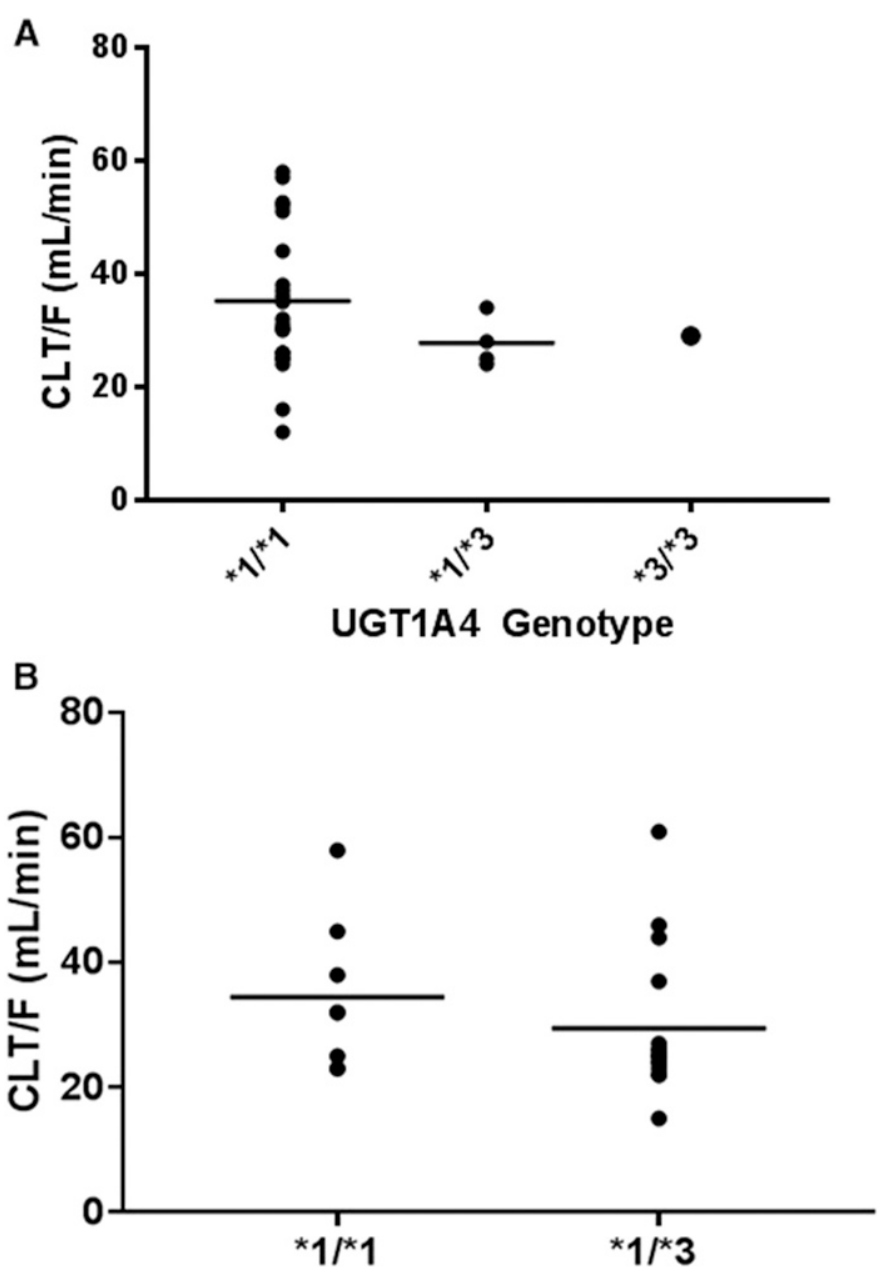

\section{CYP3A5 Genotype}

Fig. 6. Individual and mean CLT/F of BMS- 823778 in healthy Chinese subjects grouped according to (A) UGT1A4 $(P=0.28$ when $* 1 / * 3$ was compared with $* 1 / * 1)$ or (B) CYP3A5 genotype $(P=0.34$ when $* 1 / * 3$ was compared with $* 1 / * 1)$.

study, regardless of CYP2C19 predicted phenotype. There appeared a dose-dependent AI in MAD study $(\sim 21.2, \sim 7.3, \sim 4.8$, and $\sim 3.0$-fold at the doses of $2,5,12$, and $25 \mathrm{mg}$, respectively) owing to the relatively low exposure at low doses after the first dose of BMS-823778. The reason for the dose-dependent AI is unknown. One possibility is the existence of high-affinity, low-capacity binding sites (Wright et al., 2013) for BMS823778. Extensive tissue distribution of BMS-923778 to these binding sites limits the exposure of BMS- 823778 at low doses. This capacitylimited distribution could be overcome at higher dose levels or when steady state is reached. Since dose proportionality was observed at steady state regardless of CYP2C19 genotype, and the safety and efficacy are likely driven by the steady-state exposure, nonlinear PK on day 1 is not clinically significant.

Secondary peaks in the concentration-time profiles were observed in both SAD and MAD, indicating possible involvement of the biliary route in the excretion of BMS- 823778 and/or its metabolites that were recycled to parent in the gastrointestinal tract. This finding is consistent with the results from the human ADME study, where significant amounts of parent and direct glucuronide metabolite were observed in bile (Cheng et al., 2018). Enterohepatic recirculation may contribute to 


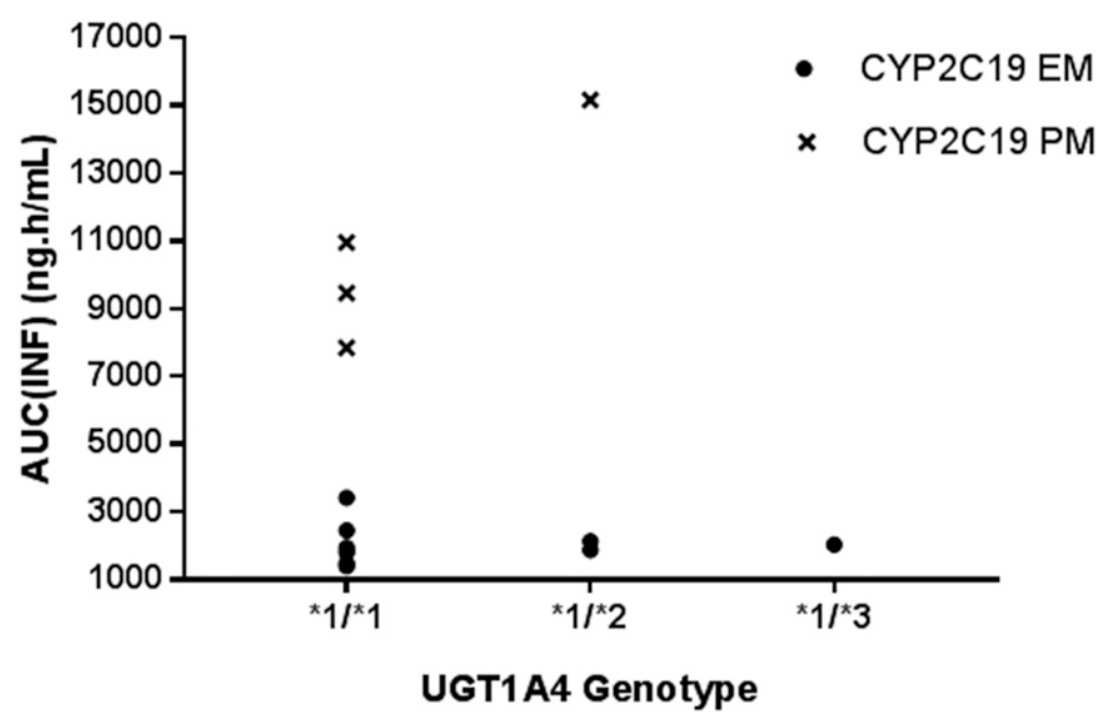

Fig. 7. Individual AUC(INF) of BMS-823778 in healthy subjects with different UGT1A4 genotype after a single oral dose of $10 \mathrm{mg}\left[{ }^{14} \mathrm{C}\right] \mathrm{BMS}-823778$. the observed relatively flat terminal phase of the concentration-time profile and longer than expected elimination half-life.

High variability of the PK was evident based on the large CV\% of the major PK parameters and significant difference in BMS-823778 exposure between subjects in the same dose panel, which prompted the investigation on the polymorphism in the clearance of BMS-823778. Even though age, gender, body weight, etc., of the participants can also contribute to the variability, that fact that individual exposure at steady state in each dose panel segregated into low and high groups suggested that polymorphic enzymes might be involved. A subsequent reaction phenotyping study demonstrated that in vitro metabolism of BMS823778 was mediated mainly by polymorphic CYP2C19, with minor contribution from CYP3A4/5 and UGT1A4 (Cheng et al., 2018). Therefore, all subjects in the Chinese and Japanese PK studies, as well as in the human ADME study, were genotyped for CYP2C19, CYP3A5, and UGT1A4 either posttreatment or before dose administration, to understand the impact of genetic polymorphisms on the PK of BMS823778 across different populations.

In both the Chinese and Japanese studies, genotyping was performed retrospectively after treatment. Plasma PK of BMS-823778 in Chinese and Japanese populations was characterized by rapid absorption and slow elimination, similar to the MAD study. $C_{\max }$ and AUC(TAU) at steady state increased largely proportionally to the dose within the tested dose range. Comparison of the exposure of BMS-823778 across different populations showed that the mean AUC(TAU) values of BMS-823778 at steady state in Chinese and Japanese subjects were comparable at the same dose level and much higher than these in the MAD study, in which most of the participants were white, similar to findings of a previous report in which the oral clearance of omeprazole in white subjects was approximately 2-fold greater than in Asian subjects (Feng et al., 2015).

An exploratory assessment of PK versus genotype suggested that the mean CLT/F of BMS-823778 directly correlated to the predicted CYP2C19 phenotype. Statistically higher clearance, shorter terminal half-life, and lower exposure of BMS-823778 were observed in CYP2C19 EM subjects than in IM or PM subjects. The results demonstrated that CYP2C19 metabolism was an important BMS823778 elimination pathway in humans, and polymorphism contributed to the interindividual variability in exposure in clinical studies. Therefore, obtaining CYP2C19 genotype information and sparse PK sampling for BMS-823778 in future phase $2 \mathrm{~b}$ studies are recommended to further characterize the PK of BMS-823778 and understand implications of CYP2C19 genotype across populations.

Genetic variants of CYP3A5 and UGT1A4 were identified in the CYP2C19 EM or IM groups in both Chinese and Japanese subjects, but not in the CYP2C19 PM group. Analysis of PK and genotype demonstrated that CYP3A5 and UGT1A4 polymorphisms did not have a statistically meaningful impact on the PK of BMS-823778 in CYP2C19 EM or IM subjects. This finding is probably due to the fact that CYP3A5 and UGT1A4 metabolism pathways were minor compared with the CYP2C19 pathway. In the ADME study, a few subjects in CYP2C19 EM group were identified as UGT1A4 genetic variants whose systemic exposures to BMS- 823778 were within the range of subjects with UGT1A4*1/*1 genotype. A single CYP2C19 PM subject with UGT1A $4 * 1 / * 2$ genotype (an intermediate metabolizer genotype for some substrates) had the highest individual BMS-823778 systemic exposure (Fig. 7). Although caution is needed in interpreting these findings because of the small number of subjects, the data did suggest that BMS-823778 is a substrate that is affected by UGT1A4 polymorphism in subjects who are devoid of CYP2C19 activity.

In summary, BMS- 823778 was safe and well tolerated in healthy subjects after single or multiple oral doses. BMS- 823778 was rapidly absorbed after oral administration, with slow clearance and long terminal half-life. Plasma exposure and clearance correlated well with the genetic variants of CYP2C19 where subjects with predicted EM phenotype had statistically greater clearance of BMS- 823778 than those with polymorphism. CYP3A5 and UGT1A4 polymorphisms did not have statistically meaningful impact on BMS-823778 PK in subjects with predicted CYP2C19 EM or IM phenotype; however, limited data suggest that exposure of BMS-823778 might be affected significantly by UGT1A4 polymorphisms in subjects with no CYP2C19 activity. Further study is needed to characterize the influence of CYP3A5 and UGT1A4 polymorphisms on the PK of BMS-823778 in CYP2C19 PMs, as well as PK in subjects with CYP2C19 *17 variation. A clear understanding of the influence of all genotypic variations in the PK of BMS-823778 is needed, especially since different ethnic groups have different levels of variation.

\section{Authorship Contributions}

Participated in research design: Hansen, Iacono.

Conducted experiments and data analysis: Gong, Hansen, Iacono.

Wrote or contributed to the writing of the manuscript: Gong, Hansen, Iacono. 


\section{References}

Anagnostis P, Katsiki N, Adamidou F, Athyros VG, Karagiannis A, Kita M, and Mikhailidis DP (2013) 11Beta-hydroxysteroid dehydrogenase type 1 inhibitors: novel agents for the treatment of metabolic syndrome and obesity-related disorders? Metabolism 62:21-33.

Anderson A and Walker BR (2013) 11 $\beta$-HSD1 inhibitors for the treatment of type 2 diabetes and cardiovascular disease. Drugs 73:1385-1393.

Cheng Y, Wang L, Iacono L, Zhang D, Chen W, Gong J, Humphreys WG, and Gan J (2018) Clinical significance of CYP2C19 polymorphisms on the metabolism and pharmacokinetics of 11ß-hydroxysteroid dehydrogenase type-1 inhibitor BMS-823778. Br J Clin Pharmacol 84 $130-141$.

Desta Z, Zhao X, Shin J-G, and Flockhart DA (2002) Clinical significance of the cytochrome P450 2C19 genetic polymorphism. Clin Pharmacokinet 41:913-958.

Ehmer U, Vogel A, Schütte JK, Krone B, Manns MP, and Strassburg CP (2004) Variation of hepatic glucuronidation: novel functional polymorphisms of the UDP-glucuronosyltransferase UGT1A4. Hepatology 39:970-977.

Feng S, Cleary Y, Parrott N, Hu P, Weber C, Wang Y, Yin OQP, and Shi J (2015) Evaluating a physiologically based pharmacokinetic model for prediction of omeprazole clearance and assessing ethnic sensitivity in CYP2C19 metabolic pathway. Eur J Clin Pharmacol 71:617-624.

Furlong MT, Ji QC, Iacono L, Dang O, Noren M, Bruce J, Aubry A-F, and Arnold ME (2016) A validated enantioselective LC-MS/MS assay for quantification of a major chiral metabolite of an achiral 11- $\beta$-hydroxysteroid-dehydrogenase 1 inhibitor in human plasma: application to a clinical pharmacokinetic study. J Chromatogr B Analyt Technol Biomed Life Sci 1022:167-172.

Goldstein JA (2001) Clinical relevance of genetic polymorphisms in the human CYP2C subfamily. Br J Clin Pharmacol 52:349-355.

Jiang X-L, Samant S, Lesko LJ, and Schmidt S (2015) Clinical pharmacokinetics and pharmacodynamics of clopidogrel. Clin Pharmacokinet 54:147-166.

Lee CR, Goldstein JA, and Pieper JA (2002) Cytochrome P450 2C9 polymorphisms: a comprehensive review of the in-vitro and human data. Pharmacogenetics 12:251-263.

Li J, Kennedy LJ, Wang H, Li JJ, Walker SJ, Hong Z, O'Connor SP, Nayeem A, Camac DM, Morin PE, et al. (2014) Optimization of 1,2,4-triazolopyridines as inhibitors of human $11 \beta$ hydroxysteroid dehydrogenase type 1 (11ß-HSD-1). ACS Med Chem Lett 5:803-808.

Mega JL, Close SL, Wiviott SD, Shen L, Hockett RD, Brandt JT, Walker JR, Antman EM, Macias $\mathrm{W}$, Braunwald E, et al. (2009) Cytochrome p-450 polymorphisms and response to clopidogrel. $N$ Engl J Med 360:354-362.
Morentin Gutierrez P, Gyte A, deSchoolmeester J, Ceuppens P, Swales J, Stacey C, Eriksson JW, Sjöstrand M, Nilsson C, and Leighton B (2015) Continuous inhibition of 11ß-hydroxysteroid dehydrogenase type I in adipose tissue leads to tachyphylaxis in humans and rats but not in mice. Br J Pharmacol 172:4806-4816.

Morgan SA, McCabe EL, Gathercole LL, Hassan-Smith ZK, Larner DP, Bujalska IJ, Stewart PM, Tomlinson JW, and Lavery GG (2014) $11 \beta$-HSD1 is the major regulator of the tissue-specific effects of circulating glucocorticoid excess. Proc Natl Acad Sci USA 111:E2482-E2491.

Morgan SA and Tomlinson JW (2010) 11 $\beta$-hydroxysteroid dehydrogenase type 1 inhibitors for the treatment of type 2 diabetes. Expert Opin Investig Drugs 19:1067-1076.

Morton NM (2010) Obesity and corticosteroids: 11ß-hydroxysteroid type 1 as a cause and therapeutic target in metabolic disease. Mol Cell Endocrinol 316:154-164.

Reimers A, Sjursen W, Helde G, and Brodtkorb E (2016) Frequencies of UGT1A4*2 (P24T) and *3 (L48V) and their effects on serum concentrations of lamotrigine. Eur J Drug Metab Pharmacokinet 41:149-155.

Smith BP, Vandenhende FR, DeSante KA, Farid NA, Welch PA, Callaghan JT, and Forgue ST (2000) Confidence interval criteria for assessment of dose proportionality. Pharm Res 17: $1278-1283$.

Sooy K, Webster SP, Noble J, Binnie M, Walker BR, Seckl JR, and Yau JLW (2010) Partial deficiency or short-term inhibition of $11 \beta$-hydroxysteroid dehydrogenase type 1 improves cognitive function in aging mice. $J$ Neurosci 30:13867-13872.

Staatz CE, Goodman LK, and Tett SE (2010) Effect of CYP3A and ABCB1 single nucleotide polymorphisms on the pharmacokinetics and pharmacodynamics of calcineurin inhibitors: part I. Clin Pharmacokinet 49:141-175.

Wojnowski L and Kamdem LK (2006) Clinical implications of CYP3A polymorphisms. Expert Opin Drug Metab Toxicol 2:171-182.

Wright DH, Stone JA, Crumley TM, Wenning L, Zheng W, Yan K, Yang AY, Sun L, Cilissen C, Ramael S, et al. (2013) Pharmacokinetic-pharmacodynamic studies of the 11 $\beta$-hydroxysteroid dehydrogenase type 1 inhibitor MK-0916 in healthy subjects. Br J Clin Pharmacol 76:917-931.

Address correspondence to: Dr. Lisa lacono, Global Regulatory Safety and Biometrics, Bristol-Myers Squibb, P.O. Box 4000, Princeton, NJ 08543. E-mail: Lisa.lacono@bms.com 